\title{
PHYSIOLOGICAL RESPONSES OF WINTER WHEAT (TRITICUM AESTIVUM L.) TO ALTERNATE IRRIGATION WITH FRESH AND BRACKISH WATER
}

\author{
CONG, X. - PANG, G. B. - XU, Z. H. ${ }^{*}$ - WANG, R. Z. \\ School of Water Conservancy and Environment, University of Jinan, Jinan 250022, PR China \\ (e-mail: congxin1994@126.com (Cong,X.); stu_panggb@ujn.edu.cn (Pang, G. B.); \\ xu4045@126.com (Xu, Z. H.); wrzhen1994@163.com(Wang, R. Z.)) \\ ${ }^{*}$ Corresponding author \\ e-mail:xu4045@126.com; phone: +86-186-6898-0091 \\ (Received $2^{\text {nd }}$ Mar 2021; accepted $14^{\text {th }}$ May 2021)
}

\begin{abstract}
Rational use of brackish water irrigation is of great significance to alleviate the shortage of agricultural fresh water resources in the Yellow River Delta of China. When brackish water is used for irrigation, it is essential to determine the extent to which the utilization of brackish water has an impact on yield $(Y)$ and understand its physiological basis. Thus, the objective of this study was to investigate the effect of drought and salt stress (fresh water irrigation treatment, fresh water and drought treatment, brackish water irrigation treatment, and brackish water and drought treatment, designated FFF, FFD, FBB and FBD, respectively) on leaf physiological characteristics, resilience, and $Y$ of winter wheat (Triticum aestivum L.) and soil water-salinity. The analysis of variance results revealed the significant effect of stress on the net photosynthetic rates $\left(P_{n}\right)$, transpiration rate $\left(T_{t}\right)$, stomatal limitation $\left(L_{s}\right)$, intercellular $\mathrm{CO}_{2}$ concentration $\left(C_{i}\right)$, water use efficiency $\left(W U E_{i}\right), K^{+} / N a^{+}$ratio, proline and soluble sugar concentrations. It can be concluded that osmotic regulation was the main mechanism for the maintenance of leaf gas exchange and yield in winter wheat under salt stress. Compared to the FFD and FBD treatments, the FBB treatment reduced water consumption (ET) and improved $Y$ without obvious salt accumulation. In conclusion, these results are important for understanding the mechanisms of salt tolerance in winter wheat and provide a scientific basis for the application of brackish water.

Keywords: brackish water, drought and salt stress, leaf physiological characteristics, osmotic regulation, $\mathrm{K}^{+} / \mathrm{Na}^{+}$ratio, water consumption, salt accumulation, yield
\end{abstract}

\section{Introduction}

Many shallow salt water resources are common in the Yellow River delta of the North China Plain, and these are considered to have great potential in agricultural production (Xu et al., 2018; Soothar et al., 2019a). As early as the 1960s, studies have shown that brackish water could be used for irrigation to provide water needed for crop growth with certain technical and economic conditions (Kelley, 1963; Harding et al., 2019). Currently, a large number of practices at home and abroad have also confirmed the view that rational use of brackish water irrigation can ensure crop yield and quality (Wiedenfeld, 2008; Chen et al., 2016; Liu et al., 2019). Accordingly, rational utilization of brackish water resources is a feasible strategy to alleviate water shortage.

Winter wheat (Triticum aestivum L.) and maize (Zea mays L.) are the most widely cultivated cereal crops and are grown on a double-cropping system in the North China Plain. Production levels of crop depend largely on irrigation. Therefore, farmers have been forced to use brackish water from shallow groundwater sources, which helps overcome drought but also increases the risk of soil salinization. In addition to the accumulation of soil salt, the effect of brackish water irrigation on crop growth and yield is one of the main problems concerning agricultural producers. There is abundant 
evidence that crops can change their normal biochemical and physiological responses to cope with salt stress. Although the physiological processes that involve transpiration and photosynthesis are well known, information regarding the effect of salinity on these processes and the regulation process of plant itself is limited. Therefore, understanding the physiological response of growth reduction under irrigation with brackish water would give us important information on brackish water irrigation.

Excessive salt will reduce the osmotic potential of the soil, resulting in the inhibition of root water absorption and crop growth (Estrada et al., 2013). Therefore, osmotic adjustment has an important function for the tolerance of plants to drought and salt stress. Plants in a soil with high salt content, whether glycophyte or halophyte, have to evolve complex mechanisms to acclimate to osmotic and ionic stresses caused by high salinity and promote their metabolic functions (Meloni et al., 2004). This is because salt stress affects all major physiological activities of crops, such as transpiration, photosynthesis, water utilization and absorption, dry matter synthesis and growth (Parida and Das, 2005). In addition to inorganic ions regulating osmotic pressure between cells, organic solutes are also compartmentalized in the cytoplasm to balance the low osmotic potential (Rahman et al., 2002). These ions play an important role in the process of anti-stress physiology in plants and frequently limit plant growth. Other studies have reported the response of proline and ion accumulation in crops under drought and salt stress (Radhouane, 2013).

In the study, winter wheat was selected as the main object. Compared to summer maize, there is less rainfall in the wheat growth period, which results in winter wheat needing large amounts of irrigation water, and the plant is classified as moderately tolerant. This study aimed to determine the effect of brackish water irrigation on the net photosynthetic rates $\left(P_{n}\right)$, transpiration rate $\left(T_{t}\right)$, stomatal limitation $\left(L_{s}\right)$, intercellular $\mathrm{CO}_{2}$ concentration $\left(C_{i}\right)$, water use efficiency $\left(W U E_{i}\right)$, the concentrations of inorganic ions $\left(\mathrm{Na}^{+}, \mathrm{K}^{+}\right)$, proline and soluble sugar, water consumption $(E T)$, and yield $(Y)$ of winter wheat and salinity of soil. The results will improve understanding of salt tolerance in winter wheat and provide an important scientific basis for the application of brackish water during wheat production in the areas rich in brackish water resources.

\section{Materials and methods}

\section{Experimental site description}

The field experiments were conducted at experimental plots $\left(37^{\circ} 34^{\prime} \mathrm{N}, 117^{\circ} 45^{\prime} \mathrm{E}\right)$ in Binzhou, Shandong Province, China (Fig. 1) during the winter wheat and summer maize growing seasons of 2015-16 and 2016-17. Winter wheat/summer maize rotation is the most important crop growing system in this area. The experimental plots belonged to the temperate continental monsoon climate. The mean annual precipitation was approximately $575.5 \mathrm{~mm}$, most of which mainly occurred during June-August. Figure 2 depicts the precipitation and evaporation during the experiment. The soil was classified as loam, having a salinity of $1.48 \mathrm{~g} \mathrm{~kg}^{-1}$, a bulk density of $1.37 \mathrm{~g} \mathrm{~m}^{-3}$ and a $\mathrm{pH}$ of 7.10.

\section{Experimental design}

Experiments included two levels of irrigation, i.e., normal irrigation treatment $(80 \mathrm{~mm})$, drought treatment $(0 \mathrm{~mm})$, and two levels of the salinity of the irrigation water, i.e., fresh water $\left(0.2 \mathrm{~g} \mathrm{~L}^{-1}\right)$, brackish water $\left(3.0 \mathrm{~g} \mathrm{~L}^{-1}\right)$, with three replicates per treatment. 
The specific irrigation treatments are shown in Table 1. The wheat growth irrigation season was divided into three main phases, that is, sowing to jointing (BBCH00-35), jointing to booting (BBCH35-55), and booting to filling (BBCH55-71). Each field plot was $0.3 \mathrm{~m}$ wide and $0.6 \mathrm{~m}$ long. A separate $0.5 \mathrm{~m}$ wide buffer zone was provided around the irrigated plots with space to protect from reciprocal effects of adjacent plots, and a 1.50-m-deep inlaid, plastic film was buried for anti-seepage (Fig. 1). The brackish water was extracted from shallow wells, and the salt content was approximately $5.0 \mathrm{~g} \mathrm{~L}^{-1}$. A brackish water desalination unit (Fig. 1) was installed to treat the brackish water to obtain fresh water that could be used for irrigation. At the same time, a pond was built to store desalinated water. The water source of brackish irrigation is the mixture of water from the pond and high salinity groundwater. A conductivity meter was used to control the salt concentration of the mixture water. The irrigation was applied through a PVC pipe with water meters at the head of the pipe to control water flow.

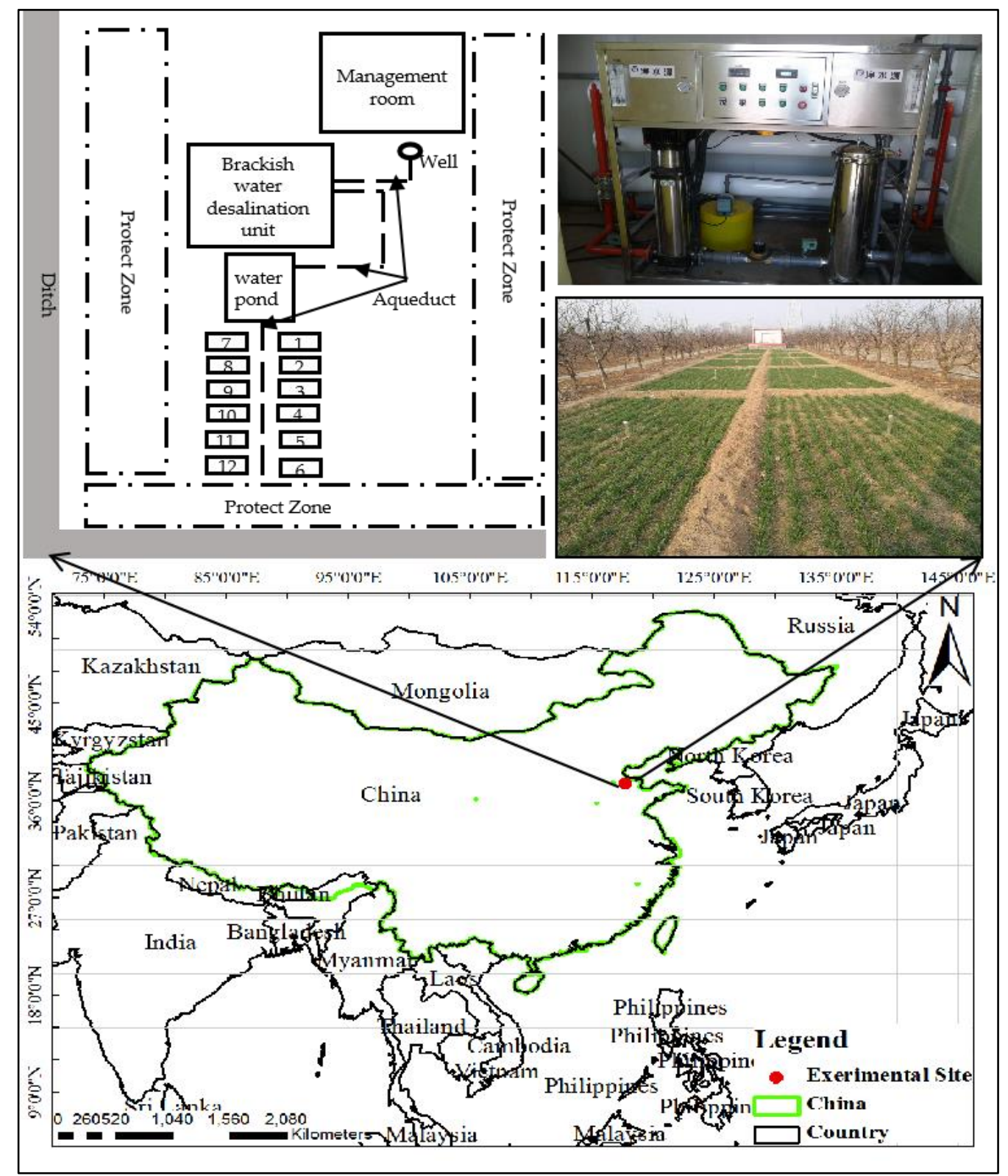

Figure 1. Location and layout of the experimental site 


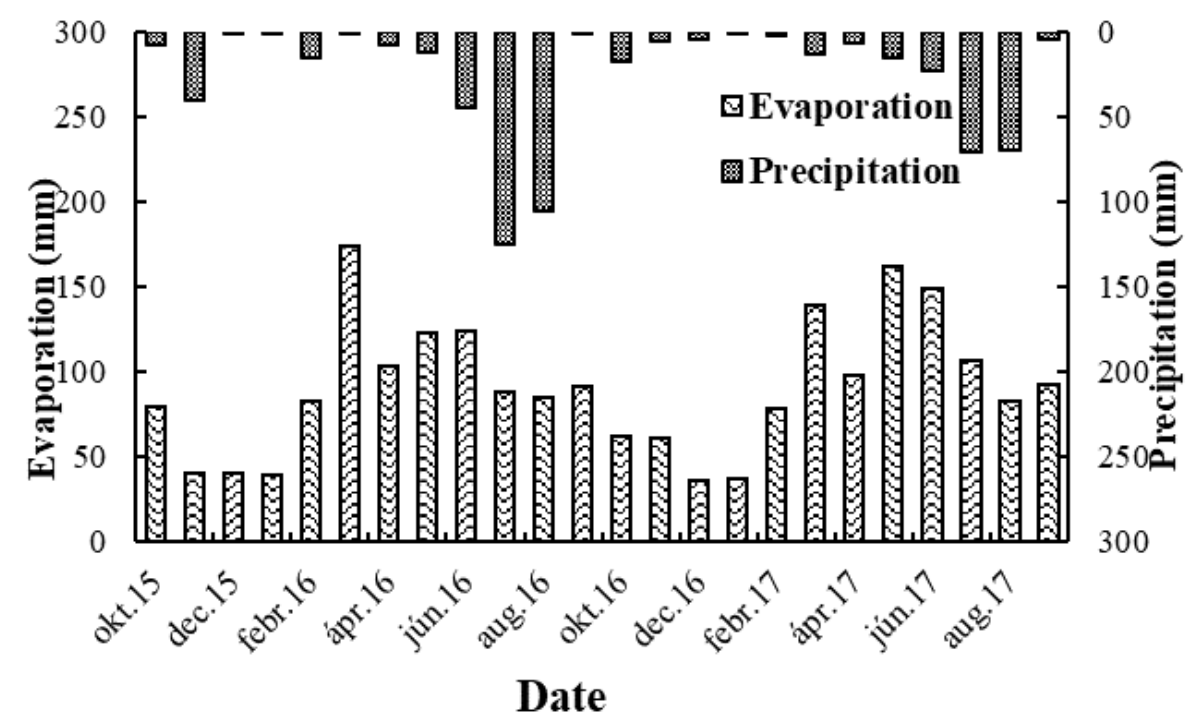

Figure 2. Precipitation and evaporation during the experiment

Table 1. Growth period and crop coefficient of winter wheat

\begin{tabular}{c|c|c|c|c}
\hline Treatment & $\begin{array}{c}\text { Jointing water } \\
(\mathbf{m m})\end{array}$ & $\begin{array}{c}\text { Booting water } \\
(\mathbf{m m})\end{array}$ & $\begin{array}{c}\text { Filling water } \\
(\mathbf{m m})\end{array}$ & $\begin{array}{c}\text { Irrigation quota } \\
(\mathbf{m m})\end{array}$ \\
\hline FFF & 80 (freshwater) & 80 (brackish water) & 80 (brackish water) & 240 \\
FFD & 80 (freshwater) & 80 (brackish water) & 0 & 160 \\
FBB & 80 (freshwater) & 80 (freshwater) & 80 (freshwater) & 240 \\
FBD & 80 (freshwater) & 80 (freshwater) & 0 & 160 \\
\hline
\end{tabular}

A local winter wheat cultivar, Jimai 22\#, was sown with a tractor-drawn seed drill using a seed rate of $120 \mathrm{~kg} \mathrm{hm}^{-2}$ with a row and plant spacing of $0.2 \mathrm{~m}$ and $0.02 \mathrm{~m}$. The plant density at seedling stage was $280 \mathrm{plant} / \mathrm{hm}^{2}$. Crop development was characterized with the $\mathrm{BBCH}$ code. Table 2 lists the sowing, harvest, and irrigation dates used for this study. The soil was irrigated with $60 \mathrm{~mm}$ of fresh water, and $10 \mathrm{~kg}$ of fermented chicken manure was applied (approximately $1.65 \% \mathrm{~N}$ ) before sowing seeds in order to ensure winter wheat germination and healthy growth. Then, $194 \mathrm{~kg} \mathrm{hm}^{-2}$ of urea fertilizer (containing $46.4 \% \mathrm{~N}$ ) was added to each plot during the green stage. The amount of nitrogen applied in the whole growth period of wheat was $286 \mathrm{~kg} \mathrm{hm}^{-2}$. Considering that the growth period of summer maize (June to October) was consistent with the rainy season, fresh water irrigation should be carried out according to the needs of maize. Other conditions (such as ploughing and loosening the soil before sowing, regular weeding, and pesticide spraying) were in line with conventional fields.

Table 2. Dates of sowing, harvest, and irrigation for two seasons

\begin{tabular}{c|c|c|c|c|c}
\hline Seasons & $\begin{array}{c}\text { Dates of } \\
\text { sowing } \\
\text { (BBCH00) }\end{array}$ & $\begin{array}{c}\text { Dates of } \\
\text { harvest } \\
\text { (BBCH99) }\end{array}$ & $\begin{array}{c}\text { Dates of jointing } \\
\text { water } \\
\text { (BBCH35) }\end{array}$ & $\begin{array}{c}\text { Dates of booting } \\
\text { water } \\
\text { (BBCH55) }\end{array}$ & $\begin{array}{c}\text { Dates of filling } \\
\text { water } \\
\text { (BBCH71) }\end{array}$ \\
\hline $2015 / 2016$ & Oct. 8, 2015 & Jun. 13, 2016 & Mar. 11, 2016 & Apr. 27, 2016 & May 22, 2016 \\
$2016 / 2017$ & Oct. 8, 2016 & Jun. 12, 2017 & Mar. 15, 2017 & Apr. 25, 2017 & May 14, 2017 \\
\hline
\end{tabular}




\section{Measurements and methods}

Determination of leaf gas exchange parameters

1) Photosynthetic characteristics

During the booting and filling stages, an Lcpro-SD portable photosynthesis system (LI-6400XT, Lincoln, NE, USA) was used to measure the $P_{n}, T_{t}$ and $C_{i}$ of fully extended flag leaves on clear days. The photosynthetic parameters of all treatments were measured twice on May 1st and May 29th in 2016, and May 1st and May 20th in 2017. The measurements were taken every two hours from 8:00 am until 6:00 pm. One flag leaves was taken from each repeated treatment were measured, and the data for each treatment was the mean of the three replications.

2) Stomatal limitation $\left(L_{s}\right)$

The most commonly used method to calculate $L_{s}$ was proposed by Berry and Downton (1982), as follows (Eq. 1):

$$
L_{s}=1-C_{i} / C_{a}
$$

where $C_{a}$ is the atmospheric carbon dioxide concentration; $C_{i}$ is the intercellular $\mathrm{CO}_{2}$ concentration.

3) Water use efficiency $\left(W U E_{i}\right)$

$W U E_{i}$ was determined as the ratio of the $P_{n}$ to $T_{t}(E q .2)$.

$$
W U E_{i}=P_{n} / T_{t}
$$

4) Relative content of chlorophyll (SPAD)

The $S P A D$ was used as a reference for the content of chlorophyll in this paper. It was determined with a SPAD instrument (SPAD-502, Minolta, Osaka, Japan).

$\mathrm{Na}^{+}$and $\mathrm{K}^{+}$, proline and soluble sugar concentrations in wheat leaf and root

For determining the ion content, whole wheat plant was collected and oven dried. In the booting and filling stages, 10 wheat plants were randomly selected. The roots of selected plants were excavated together with the soil by direct excavation method, and then washed with water and put into the blast drying oven. After desiccation, the leaves were smashed and filtrated through an 80 mesh sieve. Then, one hundred milligrams of plant samples were boiled in $50 \mathrm{~mL}$ of distilled water for 2 hours. The solution was transferred to a $50 \mathrm{~mL}$ volumetric flask to a constant volume and diluted before ion content determination using the flare photometer method (Jenway PFP7, UK) (Bao, 2000). The proline content was determined by the ninhydrin coloring method with sulfosalicylic acid extraction (Khan et al., 2000). The content of soluble sugar was determined by sulfuric acid-anthrone colorimetry (Irigoyen et al., 2010).

\section{Calculation of ET and soil electrical conductivity $\left(E C_{1: 5}\right)$}

For determining ET of winter wheat, the soil profile water content $(\omega)$ was measured at different growth periods in $100 \mathrm{~cm}$ of soil by the stoving method. For $\omega$ and $E C_{1: 5}$ determinations, soil samples were determined at $20 \mathrm{~cm}$ intervals to a depth of $100 \mathrm{~cm}$. The samples were then oven dried $\left(105^{\circ} \mathrm{C}\right)$, and $\omega$ was calculated on a dry weight basis.

The $E T(\mathrm{~mm})$ was calculated using the soil water balance as follows (Eq. 3). 


$$
E T=P+U+I+D-R-\Delta W
$$

where $P(\mathrm{~mm})$ is the rainfall, $U(\mathrm{~mm})$ is the recharge of underground water, $I(\mathrm{~mm})$ is the irrigation, $D(\mathrm{~mm})$ is the deep percolation, $R(\mathrm{~mm})$ is the runoff, $\Delta W(\mathrm{~mm})$ is the soil moisture content for the $0 \sim 100 \mathrm{~cm}$ soil depth between different growth periods.

$U$ was assumed to be negligible because the level of the water table near the experimental field was $>20 \mathrm{~m}, D$ was assumed to be negligible since the water storage capacity of soil at the experimental site was high and normally exceeded the rainfall volume required to saturate that capacity, and no runoff was generated at the experimental field, so $U, D$ and $R$ were neglected. Eq. 3 was simplified to Eq. 4:

$$
E T=P+I-\Delta W
$$

The formula of $W$ was shown as follows (Eq. 5):

$$
W=h \times \rho \times \omega / 10
$$

where $h(\mathrm{~cm})$ is the soil depth, and $\rho\left(\mathrm{g} \mathrm{cm}^{-3}\right)$ is the soil bulk density.

The change in the salt storage in different soil layers was taken as an index for evaluating the effect of brackish water irrigation. Soil samples were stored in a plastic bag, transported to the laboratory, and then air-dried, ground and sieved through a $2 \mathrm{~mm}$ sieve. To prepare soil extractions, $100 \mathrm{~mL}$ of distilled water was added to every $20 \mathrm{~g}$ of processed soil sample (water: soil is 5:1) and mixed properly using a reciprocating shaker $\left(150 \sim 180\right.$ times $\left.\mathrm{min}^{-1}\right)$ for $5 \mathrm{~min}$. $E C_{1: 5}$ was measured using a conductivity meter (DDS307, INESA Scientific Instrument Co., Ltd., Shanghai, China).

\section{Calculation of the relative yield}

One sample plot of $1 \mathrm{~m}^{2}$ was harvested, and the grains were separated manually. Subsequently, the grains were air-dried, and the yield was recorded. The yield of each treatment was determined as the mean of the three replications. The ratio of the yield under different treatments to that under control conditions was recorded as the relative yield.

\section{Data analysis}

Analysis of variance (ANOVA) was conducted to determine the significance of the different irrigation management techniques on leaf gas exchange parameters and ion concentrations using SPSS Statistics (Statistical Product and Service Solutions, version $16, I B M$, New York, USA). To test the differences between mean values of data in the paper, the least significant difference test $(L S D)$ was computed, and the resultant values were expressed as letters. Water quality, and water quantity were considered fixed effect. Correlation coefficients between pairs of yield, gas exchange and osmotic concentration were examined using Pearson's correlation coefficient at the 5 or $1 \%$ significance level. 


\section{Results}

\section{Effect of water salinity on the leaf gas exchange parameters}

Combined ANOVA results showed that all gas exchange parameters were influenced by water quality, water quantity and the interaction of the two variables at the filling stage (Table 3). Table 3 showed that the parameters underwent a significant change under FFD, FBB and FBD treatment compared with the FFF treatment. The $P_{n}$ decreased significantly in the order FFF $>$ FBB $>$ FFD $>$ FBD, which means the drought stress treatments had a larger effect than the salt stress treatments on $P_{n}$. Total $T_{t}$ ranged from 14.20 to $14.80 \mathrm{mmol} \mathrm{m}^{-2} \mathrm{~s}^{-1}$ in the FFD, and 12.10 to $12.30 \mathrm{mmol} \mathrm{m}^{-2} \mathrm{~s}^{-1}$ in the FBB and 13.80 to $14.00 \mathrm{mmol} \mathrm{m}^{-2} \mathrm{~s}^{-1}$ in the FBD, which was significantly lower than the FFF (15.30 to $15.50 \mathrm{mmol} \mathrm{m}^{-2} \mathrm{~s}^{-1}$ ). The $C_{i}$ was $4.68 \%$ and $2.80 \%$ in FFD and FBD, which was lower than in FFF, and $3.14 \%$ in FBB, which was higher than in FFF. The $L s$ of FFD, FBB and FBD were $13.70 \%, 9.59 \%$ and $9.59 \%$ higher than that of FFF, respectively. The SPAD values of FFD, FBB and FBD were 9.00\%, $8.28 \%$ and $12.65 \%$ lower than the FFF treatments, respectively. The $W U E_{i}$ of irrigated wheat (FFF and FBB) was higher than that of no irrigation (FFD and FBD). Through the above analysis, we could conclude that brackish water irrigation can result in significant changes in gas exchange parameters.

Table 3. Combined analysis of variance for leaf gas exchange under different treatment at the filling stage of wheat

\begin{tabular}{|c|c|c|c|c|c|c|c|}
\hline $\mathbf{T}$ & Year & $\begin{array}{c}P_{n} \\
\left(\mu \mathrm{mol} \cdot \mathrm{m}^{-2} \cdot \mathrm{s}^{-1}\right)\end{array}$ & $\begin{array}{c}T_{t} \\
\left(\mathrm{mmol}^{\prime} \cdot \mathrm{m}^{-2} \cdot \mathrm{s}^{-1}\right)\end{array}$ & $\begin{array}{c}C_{i} \\
\left(\mu \mathrm{mol} \cdot \mathrm{mol}^{-1}\right) \\
\end{array}$ & $L_{s}$ & $S P A D$ & $\begin{array}{c}W U E_{i} \\
\left(\mu \mathrm{mol} \cdot \mathrm{mmol}^{-1}\right)\end{array}$ \\
\hline FFF & \multirow{4}{*}{$2015-16$} & $46.50 \mathrm{a}$ & $15.50 \mathrm{a}$ & $281.33 \mathrm{c}$ & $0.41 \mathrm{~b}$ & $60.02 \mathrm{a}$ & $3.00 \mathrm{c}$ \\
\hline FFD & & $42.50 \mathrm{c}$ & $14.20 \mathrm{~b}$ & $278.58 \mathrm{c}$ & $0.43 \mathrm{~b}$ & $59.12 \mathrm{a}$ & $2.99 \mathrm{~b}$ \\
\hline FBB & & $43.10 \mathrm{~b}$ & $12.10 \mathrm{c}$ & $291.00 \mathrm{~b}$ & $0.45 \mathrm{a}$ & $57.89 \mathrm{~b}$ & $3.56 \mathrm{a}$ \\
\hline FBD & & $42.30 \mathrm{c}$ & $13.80 \mathrm{bc}$ & $279.57 \mathrm{c}$ & $0.43 \mathrm{~b}$ & $57.15 \mathrm{~b}$ & $3.07 \mathrm{~b}$ \\
\hline FFF & \multirow{4}{*}{ 2016-17 } & $47.80 \mathrm{a}$ & $15.30 \mathrm{a}$ & $308.33 \mathrm{a}$ & $0.32 \mathrm{c}$ & $50.98 \mathrm{c}$ & $3.12 \mathrm{~b}$ \\
\hline FFD & & $43.10 \mathrm{~b}$ & $14.80 \mathrm{~b}$ & $283.50 \mathrm{c}$ & $0.40 \mathrm{~b}$ & $41.89 \mathrm{~d}$ & $2.91 \mathrm{c}$ \\
\hline FBB & & $44.20 \mathrm{~b}$ & $12.30 \mathrm{c}$ & $317.17 \mathrm{a}$ & $0.35 \mathrm{c}$ & $43.92 \mathrm{~d}$ & $3.59 \mathrm{a}$ \\
\hline FBD & & $42.80 \mathrm{c}$ & $14.00 \mathrm{~b}$ & $293.56 \mathrm{~b}$ & $0.37 \mathrm{c}$ & $39.81 \mathrm{~d}$ & $3.06 \mathrm{~b}$ \\
\hline \multirow{3}{*}{$\mathrm{F} \uparrow$} & Water quality & $96.18^{* *}$ & $8.89^{* *}$ & 0.215 & $18.116^{* *}$ & 4.200 & $146.386^{* *}$ \\
\hline & Water quantity & $45.534^{* *}$ & $200.556^{* *}$ & $23.553^{* *}$ & $140.741^{* *}$ & 0.684 & $559.807^{* *}$ \\
\hline & Quality $\times$ Quantity & $34.201^{* *}$ & $93.889^{\text {** }}$ & 4.122 & 0.992 & 1.770 & $234.867^{* *}$ \\
\hline
\end{tabular}

$\dagger *$-significant at $\mathrm{P}<0.05$; **-significant at $\mathrm{P}<0.01$. Values are the average of nine replications. Different lowercase letters following values within same columns mean significant difference among treatments at 0.05 level. The same in Tables 4-5

Different irrigation management strategies significantly affected the leaf gas exchange parameter structure (Fig. 3). Principal coordinates analysis showed that the two-year samples from the same treatment were grouped together. The PCoA1 and PCoA2 axes explained 56.01 and $26.76 \%$ of the total variability, respectively. The differences of gas and yield with different irrigation strategies of wheat were compared and analyzed for two years, which indicated that the growth parameters of each treatment were weak in the second year. The reason for this phenomenon is that the rainfall in the second wheat growth period was nearly $25 \%$ less than that in the previous year. From the parameter values in one year, the yield of the FBB treatment decreased slightly compared with that 
of the FFF treatment but increased compared with the FFD treatment. There was a significant decrease in $C_{i}$ and $T_{t}$ and an increase in $W U E_{i}$ and $S P A D$ with FBB disposal, indicating the clear adaptation of winter wheat to brackish water irrigation. Overall, the adapted FBB exhibited physiological mechanisms capable of sustainably maintaining their yield capacity.

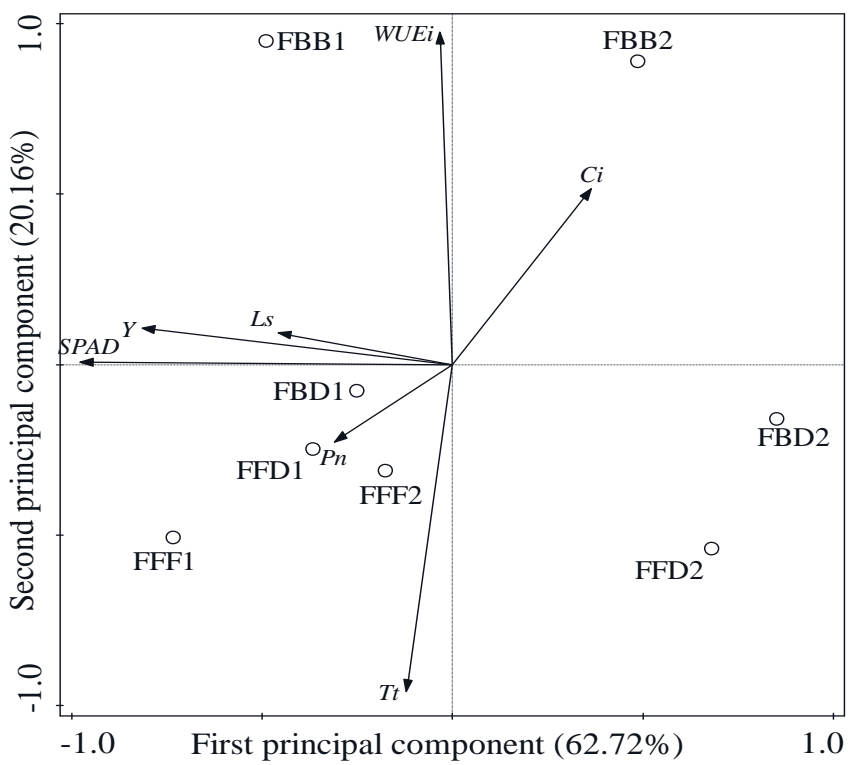

Figure 3. Biplots of the first two components of the principal component analysis for yield and leaf gas exchange parameters under different treatment in 2015-2017

\section{Effect of water salinity on the $\mathrm{Na}^{+}, \mathrm{K}^{+}$, proline and soluble sugar concentration}

A difference was observed under salt stress compared with fresh water in wheat leaves at the booting stage (Fig. 4a). However, the difference has been significantly reduced compared with the root (Fig. 4b). This is because salt stress induced a significant increase in $\mathrm{Na}^{+} / \mathrm{K}^{+}$in wheat roots. During this period, the roots of crops need to absorb a large amount of water to maintain crop growth. A substantial increase in the $\mathrm{Na}^{+} / \mathrm{K}^{+}$ratio of leaves was observed when wheat was exposed to salt or drought stress compared to the control at the filling stage. Under drought stress and salt stress, the $\mathrm{Na}^{+} / \mathrm{K}^{+}$ratios increased by $20.71,30.78 \%$ and $38.71 \%$ in FFD, FBB and FBD, respectively, compared with FFF.

In this investigation, proline and soluble sugar concentrations increased significantly under drought and salt stresses (Fig. 5). The accumulation of proline in leaves was significantly affected by salinity (Fig. $5 a$ ). At the booting stage, salt stress led to significant $(P<0.01)$ increases in the leaf proline content, which ranged from 5.25 to 6.10 $\mathrm{mg} \mathrm{g}^{-1}$. At the filling stage, in the absence of irrigation treatment (FFD, FBD), the proline concentrations were higher in plants without drought stress. Similarly, compared with fresh water irrigation (FFD, FFF), salt brought by brackish water irrigation also increased the accumulation of proline in wheat to cope with salt stress.

Analysis of the soluble sugar concentration (Fig. 5b) in leaves of wheat showed that the content of FB at the booting stage significantly increased compared with that of the FF. At the filling stage, soluble sugar concentrations in FFD, FBB and FBD treatments 
were higher than that in FFF, which indicated that a large amount of soluble sugar accumulated to resist drought and salt stress. The highest soluble sugar was observed at the filling stage in FBD.

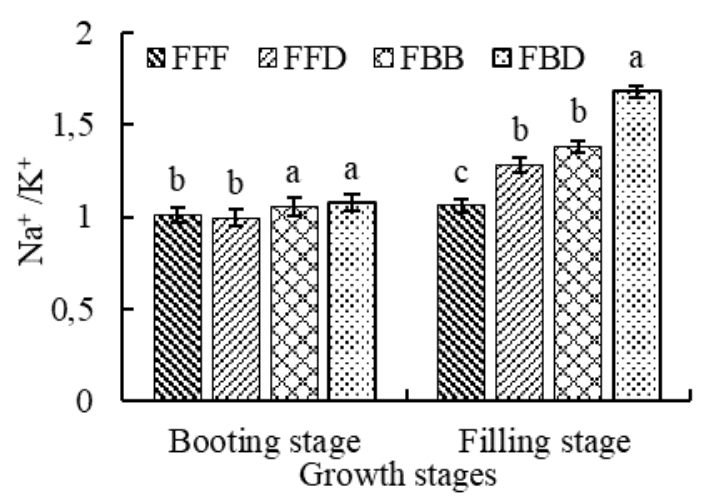

(a)

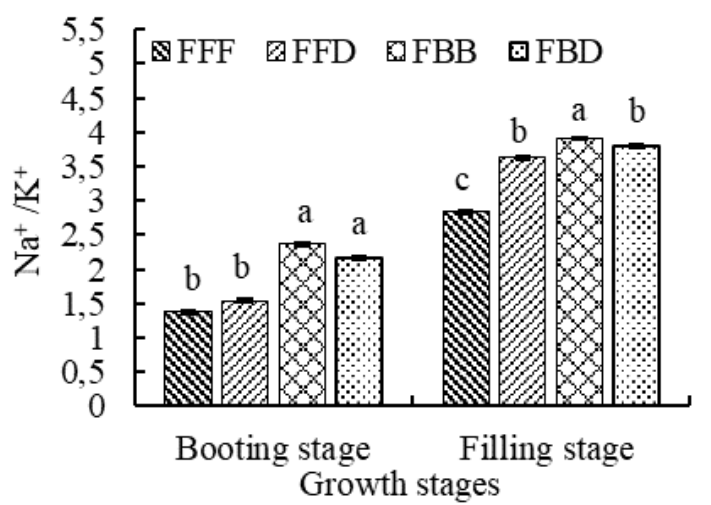

(b)

Figure 4. The $\mathrm{Na}^{+} / \mathrm{K}^{+}$of leaves (a) and roots (b) under different treatments. Error bars indicate standard error of the mean based on ten replicates. Different letters above the columns for the same repeated treatment indicate significant differences among the treatments at 0.05 level. The same in Figures 5-6

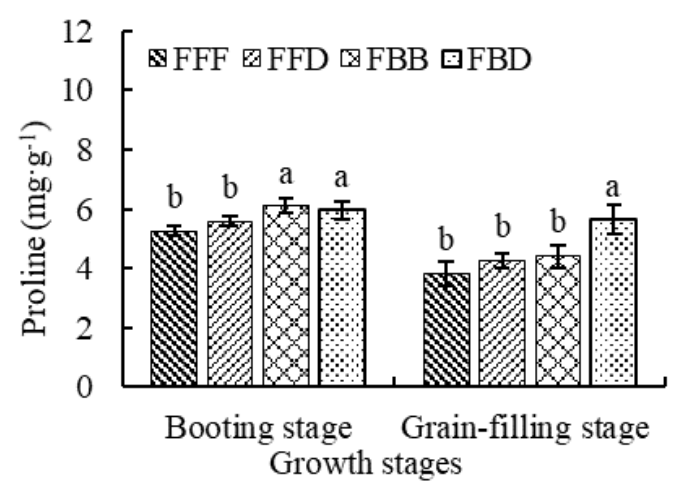

(a)

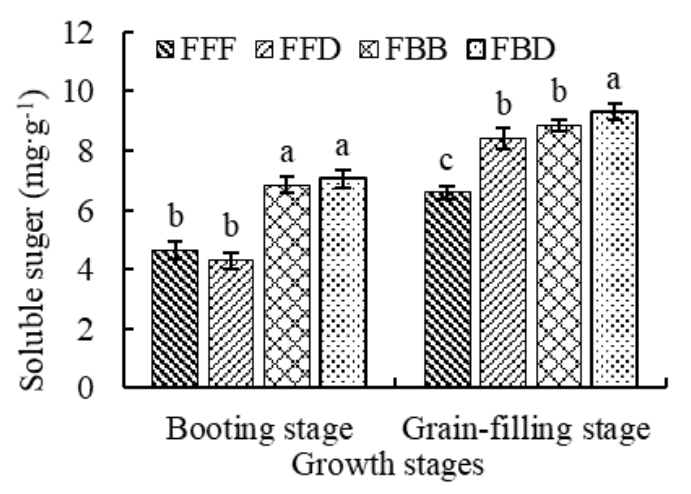

(b)

Figure 5. The proline (a) and soluble sugar accumulation of leaves (b) under different treatments

\section{Effect of water salinity on ET}

It can be seen from Table 4 that the ET in the whole growth period of winter wheat was greater than the actual irrigation amount, which indicated that not only a large part of irrigation water was consumed in the process of wheat growth but also a part of the water content from the soil layer was consumed. The ET of the four treatment areas in 2017 were reduced by $8.3 \%, 8.1 \%, 6.7 \%$, and $10.2 \%$, respectively, compared with those of 2016. The reason for this difference was the climate difference in the past two years. It can also be seen from Figure 2 that the evaporation water consumption in 2016 was higher than that in 2017. But, there was similarity in the ET and the water consumption structure between the two study years. In terms of $E T$, the results showed that there were significant differences between it of wheat under four irrigation treatments. In 2016, the 
ET was $485.11 \mathrm{~mm}$ under FFF irrigation and $431.89 \mathrm{~mm}$ under FFD. Water deficit reduced the $E T$ of wheat by $10.97 \%$. At the same time, the $E T$ was $453.33 \mathrm{~mm}$ under FBB, which indicated that salt stress could reduce the water consumption of wheat. In terms of water consumption structure, different irrigation treatments showed less of a difference in the use of rainwater resources, compared with the utilization of irrigation water and soil water storage. The water consumption of FBB treatment was mainly irrigation water, and the consumption proportion was as high as $53.98 \%$, while the consumption proportion of soil storage water was only $24.74 \%$. In FBB treatment, the irrigation water supply was sufficient, but the soil water could not be fully utilized by wheat because of the significant increase in the soil salt content and low osmotic potential.

Table 4. Combined analysis of variance for leaf gas exchange under different treatment at the filling stage of wheat

\begin{tabular}{|c|c|c|c|c|c|c|c|c|}
\hline \multirow{3}{*}{ Year } & \multirow{3}{*}{ Treatment } & \multicolumn{6}{|c|}{ Water source of total water consumption } & \multirow{3}{*}{$\begin{array}{l}E T \\
\mathrm{~mm} \\
\end{array}$} \\
\hline & & \multicolumn{3}{|c|}{ Total $(\mathbf{m m})$} & \multicolumn{3}{|c|}{ Proportion (\%) } & \\
\hline & & $\boldsymbol{P}$ & $I$ & $\Delta \mathbf{W}$ & $\boldsymbol{P}$ & $I$ & $\Delta \mathbf{W}$ & \\
\hline \multirow{4}{*}{2016} & FFF & 101.2 & 240 & 143.91 & 20.86 & 49.47 & 29.67 & $485.11 \mathrm{a}$ \\
\hline & FFD & 101.2 & 160 & 170.69 & 23.43 & 37.05 & 39.52 & $431.89 \mathrm{c}$ \\
\hline & FBB & 101.2 & 240 & 112.13 & 22.32 & 52.94 & 24.74 & $453.33 \mathrm{~b}$ \\
\hline & FBD & 101.2 & 160 & 162.9 & 23.86 & 37.73 & 38.41 & $424.10 \mathrm{c}$ \\
\hline \multirow{4}{*}{2017} & FFF & 78.4 & 240 & 126.24 & 17.63 & 53.98 & 28.39 & $444.64 \mathrm{a}$ \\
\hline & FFD & 78.4 & 160 & 158.39 & 19.76 & 40.32 & 39.92 & $396.79 \mathrm{c}$ \\
\hline & FBB & 78.4 & 240 & 104.38 & 18.54 & 56.77 & 24.69 & $422.78 \mathrm{~b}$ \\
\hline & FBD & 78.4 & 160 & 142.57 & 20.58 & 42.00 & 37.42 & $380.97 \mathrm{c}$ \\
\hline \multirow{3}{*}{$\mathrm{F}$} & \multirow{3}{*}{\multicolumn{7}{|c|}{$\begin{array}{c}\text { Water quality } \\
\text { Water quantity } \\
\text { Quality } \times \text { Quantity }\end{array}$}} & $4.827^{*}$ \\
\hline & & & & & & & & $23.722^{* *}$ \\
\hline & & & & & & & & 0.809 \\
\hline
\end{tabular}

\section{Effect of water salinity on the soil salinity}

The salt build-up in the soil depth of $0 \sim 100 \mathrm{~cm}$ by alternate irrigation with fresh and brackish water during the winter wheat and summer maize rotation was depicted in Figure 6. At sowing, accumulated soil $E C_{1: 5}$ values in the crop root zone $(0 \sim 100 \mathrm{~cm})$ were $0.61,0.61,0.58$ and $0.60 \mathrm{dS} \mathrm{m}^{-1}$ for FFF, FFD, FBB and FBD during 2015-2016, respectively. There was serious salt accumulation in winter wheat from sowing to jointing water, which may be the result of shallow saline groundwater, low rainfall quantity and intense evapotranspiration. Soil $E C_{1: 5}$ after booting water increased by $16.6 \%$ and $17.5 \%$ in FBB and FBD treatments, and decreased by $11.6 \%$ and $10.5 \%$ in FFF and FFD treatments compared with that before irrigation, respectively. In the third irrigation, the plots under FFF and FBB treatments showed a $14.2 \%$ and $13.2 \%$ reduction, respectively, whereas the values for plots irrigated with FFD and FBD increased by $32.0 \%$ and $24.5 \%$, which indicated that irrigation with brackish water may inhibit salt accumulation in the surface layer caused by the capillary rise of groundwater, strong root-water uptake and soil evaporation. At the end of the wheat growing period, salinity of the FFF, FFD and FBB was 3.7, 6.4, 5.2 and 9.3 times that at sowing, respectively. Irrigation with a large quantity of precipitation at the growth period of maize flushed the accumulated salt out 
of the root zone, and the $E C_{1: 5}$ decreased again to background levels. Soil $E C_{1: 5}$ after harvest decreased by $46.6 \%$ in FFF and increased by $14.0 \%, 9.6 \%$ and $15.8 \%$ in FFD and FBB treatments compared with that before wheat sowing, respectively. Similarly, in 2016 2017, the change process of soil salinity was similar to that of the previous year. However, the accumulation of salt was more serious than that of the previous year, mainly because the heavy rainfall in the previous year helped to leach salt from the root zone. According to the salt accumulation after two years of irrigation with fresh and brackish water in the crop root zone $(0 \sim 100 \mathrm{~cm})$, although some salts at the surface layer were leached into the deeper soil layer and groundwater by precipitation in the summer maize growth period, salt accumulation occurred in all three treatments, with the accumulation degree of $\mathrm{FFF}<\mathrm{FBB}<\mathrm{FFD}<\mathrm{FBD}$.
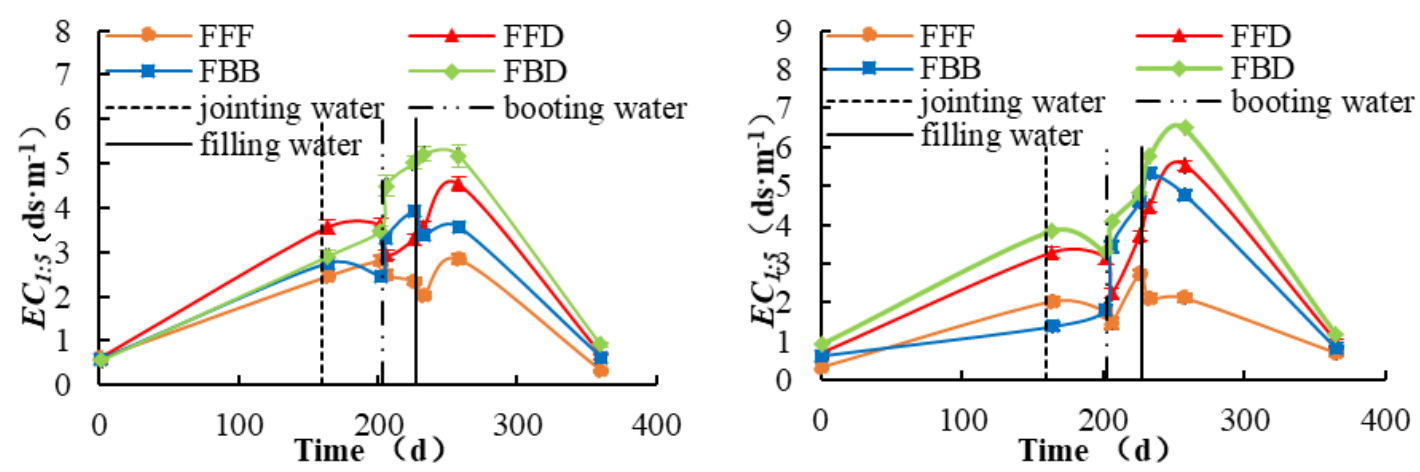

Figure 6. Accumulated salt with different water irrigation treatments for $0 \sim 100 \mathrm{~cm}$

\section{Effect of water salinity on the yield}

The two-year winter wheat yield data were shown in Table 5. As seen, the relative yields in the two years showed differences under different treatments, following the order of $\mathrm{FBD}<\mathrm{FFD}<\mathrm{FBB}=\mathrm{FFF}$. There was no significant difference in yield between FBB and FFF treatment. Yield change was significantly affected by water quality and quantity. In the second year, the relative yield of FBB decreased, which may be due to the increased effect of salt accumulation on the yield.

Table 5. Effect of irrigation treatment on yield and relative yield for the two seasons

\begin{tabular}{c|c|c|c|c}
\hline \multirow{2}{*}{ Treatment } & \multicolumn{2}{|c|}{ Yield $\left(\mathbf{k g} \cdot \mathbf{h m}^{-2}\right)$} & \multicolumn{2}{c}{ Relative Yield } \\
\cline { 2 - 5 } & $\mathbf{2 0 1 6}$ & $\mathbf{2 0 1 7}$ & $\mathbf{2 0 1 6}$ & $\mathbf{2 0 1 7}$ \\
\hline FFF & $7055.95 \mathrm{a}$ & $6683.33 \mathrm{a}$ & 1 & 1 \\
FFD & $5782.14 \mathrm{c}$ & $5321.43 \mathrm{c}$ & 0.819 & 0.796 \\
FBB & $6642.86 \mathrm{~b}$ & $5798.81 \mathrm{~b}$ & 0.941 & 0.868 \\
FBD & $5712.02 \mathrm{c}$ & $5290.74 \mathrm{c}$ & 0.810 & 0.792 \\
\hline \multirow{2}{*}{ Water quality } & \multicolumn{2}{c}{$117.968^{* *}$} \\
F & \multicolumn{2}{c}{$653.492^{* *}$} \\
& \multicolumn{2}{c}{ Quater quantity } & $41.479^{* *}$ \\
\hline
\end{tabular}




\section{Discussion}

Photosynthesis is the basis of crop yield formation, which is sensitive to the changes of environmental stress and can effectively be used to evaluate the resistance of crops to environmental stress. The results showed that the effect of drought stress on photosynthesis was greater than that of salt stress. According to the pore limit analysis method proposed by Farquhar (1982), $C_{i}$ and $L_{s}$ can be used to determine the cause of $P_{n}$ reduction. At the filling stage, it was obvious that the decrease in $P_{n}$ under drought stress (FFD) was due to the stomatal restriction. Although the $L_{s}$ of FBB was higher than that of FFF, the $C_{i}$ was relatively high (Table 3 ). This indicated that $P_{n}$ was mainly restricted by nonstomatal factors at this stage. This may be related to the degradation of chlorophyll under salt conditions (Zhu et al., 2018). $W U E_{i}$ is an important characteristic parameter in evaluating the process of individual water use of plants, which is of great significance to the study of plant responses to environmental change and environmental adaptability (Boese et al., 2017). According to formula (2), the $W U E_{i}$ was mainly determined by $P_{n}$ and $T_{t}$, and the variation of the value depended on the sensitivity of the two components $\left(P_{n}\right.$ and $\left.T_{t}\right)$ with respect to salt and water changes. We found that $W U E_{i}$ increased significantly as salt stress increased, as shown in Figure 7. Compared with the fresh water treatment, the change in the slope of the $W U E_{i}-P_{n}$ response curve was significantly larger than that of the $W U E_{i}-T_{t}$ response curve in the brackish water treatment, which indicated that increasing brackish water promoted the responses of the $W U E_{i}-P_{n}$ and $W U E_{i}-T_{t}$ curve growths. The results indicated that the response of $P_{n}$ to salinity was lower than that of $T_{t}$, and the $P_{n}$ of brackish water treatments remained higher under the condition of lower $T_{t}$, which was the main reason for the increase in the $W U E_{i}$ under brackish water irrigation.

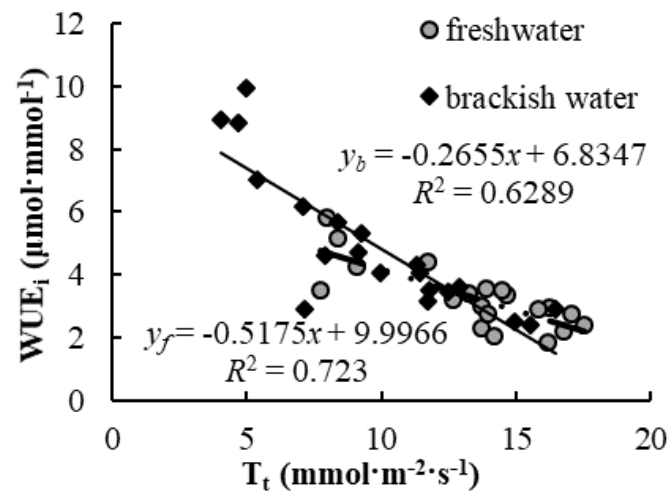

(a) Relationship between $W U E_{i}$ and $T$

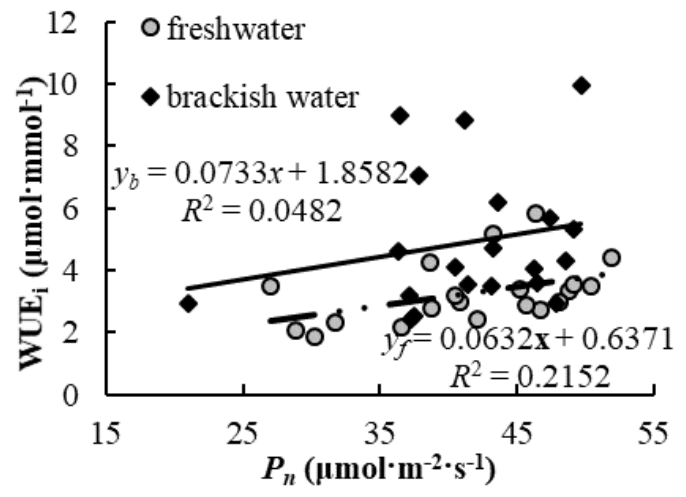

(b) Relationship between $W U E_{i}$ and $P_{n}$

Figure 7. Effect of $T_{t}(a)$ and $P_{n}(b)$ factors on $W U E_{i}$

Photosynthetic constraints due to drought and salt during the reproductive stage cause limitations on the availability of assimilates to the grains, thereby leading to reduced grain yield (Table 6). In this study, although brackish water irrigation severely suppressed winter wheat physiology at the booting stage, the FBB treatments seemed to catch up in growth during the filling stages and even achieved higher yield than FFD (Table 5). Moreno et al. (2007) also reported that brackish water irrigation increased the yield to different degrees compared with dry farming. The reason for this phenomenon was that winter wheat can resist salt stress through its own regulation. 
Table 6. Correlation coefficients $\left(R^{2}\right)$ between pairs of ion concentrations and physiological attributes under salt stress

\begin{tabular}{|c|c|c|c|c|c|c|c|c|c|c|}
\hline & $\mathrm{Na}^{+} / \mathrm{K}^{+}$ & Proline S & luble sugar & $P_{n}$ & $T_{t}$ & $C_{i}$ & $L_{s}$ & SPAD & $W U E_{i}$ & $\mathbf{Y}$ \\
\hline $\mathrm{Na}^{+} / \mathrm{K}^{+}$ & 1 & & & & & & & & & \\
\hline Proline & $0.992^{* *}$ & 1 & & & & & & & & \\
\hline Soluble sugar & $0.995^{* *}$ & $0.992^{* *}$ & 1 & & & & & & & \\
\hline $\boldsymbol{P}_{n}$ & $-0.780^{*}$ & $-0.850^{* *}$ & $-0.788^{*}$ & 1 & & & & & & \\
\hline$T_{t}$ & $-.759^{*}$ & $-0.738^{*}$ & $-0.811^{* *}$ & 0.455 & 1 & & & & & \\
\hline$C_{i}$ & 0.046 & -0.052 & 0.077 & 0.71 & -0.525 & 1 & & & & \\
\hline $\boldsymbol{L}_{s}$ & 0.608 & 0.662 & 0.561 & $-0.726^{*}$ & 0.005 & $-0.736^{*}$ & 1 & & & \\
\hline$S P A D$ & $-.833^{* *}$ & $-0.892^{* *}$ & $-0.831^{* *}$ & $0.992^{* *}$ & 0.459 & 0.48 & $-0.862^{* *}$ & 1 & & \\
\hline$W U E_{i}$ & 0.473 & 0.399 & 0.515 & 0.048 & $-0.858^{* *}$ & $0.884^{* *}$ & -0.41 & 0.02 & 1 & \\
\hline $\mathbf{Y}$ & $-0.768^{*}$ & $-0.833^{* *}$ & $-0.757^{*}$ & $0.982^{* *}$ & 0.333 & 0.59 & $-0.917^{* * *}$ & $0.991^{* *}$ & 0.153 & 1 \\
\hline
\end{tabular}

In order to maintain a stable internal environment and ensure the normal growth and development of crops, the content of soluble substances and the activity of active oxygen scavenging enzymes were increased in response to stress. $\mathrm{Na}^{+}, \mathrm{K}^{+}$, soluble protein and soluble sugar are all involved in the osmotic regulation of winter wheat. The lower $\mathrm{Na}^{+} / \mathrm{K}^{+}$ratios were important criteria for salt tolerance assessment. In our research, the change in the $\mathrm{Na}^{+} / \mathrm{K}^{+}$ratios under salt stress (Fig. 4) were in line with the general view that the increased treatment of salinity induces an increase in $\mathrm{Na}^{+} / \mathrm{K}^{+}$ratios (Gadallah, 1999; Khan, 2001). Winter wheat exhibited strong salt tolerance. Increasing osmolyte contents, such as proline and soluble sugars, can be an attempt to counter osmotic stress, reducing the osmotic potential of the cell protoplasm. This reduction is beneficial for stabilizing cellular membranes and maintaining turgor, and ultimately relieves ion toxicity and physiological drought (Patade et al., 2011; Selim et al., 2019). Our results showed that under drought and stress, the concentrations of proline and soluble sugar clearly increased (Fig. 5), and winter wheat can reduce cell osmotic potential by osmotic adjustments when drought and saline stress were at lower levels. The correlation coefficients between ion concentration and different physiological attributes under salt stress were shown in Table 6. As expected, high correlation coefficients were found between ion concentration and all photosynthetic parameters of winter wheat except $C_{i}$, $L_{s}$ and $W U E_{i}$, when brackish water was used for irrigation. This showed that the accumulation of inorganic and organic solutes was the main mechanism for the maintenance of leaf gas exchange and yield in winter wheat under salt stress.

Reasonable irrigation water quantity and irrigation water quality are the premise to ensure the sustainable development of irrigation agriculture. Shani and Dudley (2001) and Ben-Hur et al. (2001) found that under salt stress, osmotic potential hindered root water absorption, resulting in more water remaining in the soil. In this study, the difference in soil water storage between FBB treatment and FFF treatment was obvious (Table 4). Less water storage consumption in the soil layer is the result of crop water absorption difficulty. Many studies have reported that irrigation with brackish water can increase the risk of salt build-up in the soil (Basile et al., 2012; Liu et al., 2016). Relevant studies also showed that suitable brackish water irrigation can not only provide the water needed for crop growth but also wash out part of the salt in the root layer of the crop to ensure crop growth (Wang et al., 2002). In the present study, we found that deficit 
irrigation (FFD) and brackish water irrigation (FBB) both caused salt accumulation. And, at the end of the wheat growth period the following year, the salt accumulation of FFD was higher than that of FBB (Fig. 6). Similarly, many studies have shown that the higher soil salinity caused by brackish water was reduced markedly to a low level after fresh water irrigation (Kiani and Mirlatifi, 2012; Singh, 2014). In this study, salt accumulation also declined significantly after the end of the maize growth period (Fig. 6). This implied that although salts accumulated in the main root zone during the brackish water irrigation period, later fresh water irrigation can help to flush excess salts, thus lowering the soil salinity. Soothar et al. (2019b) also showed that intermittent irrigation can effectively reduce the occurrence of local accumulation of soil salt, thus ensuring the sustainable use of soil.

In this study, under the premise of ensuring the yield, there was no obvious salt accumulation from the whole cycle of winter wheat and summer corn in the brackish water irrigation treatment, and even the water consumption was reduced with the same amount of fresh water irrigation. This confirmed that the salinity of brackish water used in this study was $3.00 \mathrm{~g} \mathrm{~L}^{-1}$, which was safe. It has been proven that high yield can be obtained by irrigation with $3 \sim 5.00 \mathrm{~g} \mathrm{~L}^{-1}$ brackish water for the growth of wheat (Wang et al., 2010) and maize (Zhu et al., 2018) in the North China Plain in other studies.

\section{Conclusion}

Salinity and water effect with regard to tolerance, physiological response, and salt profit and loss in soil were investigated in detail in this study. This study reported the results from only a two-year experiment. Therefore, the cumulative effect of long-term alternate irrigation on soil salinity and agricultural productivity were not included. In two years, this study indicated that $3.0 \mathrm{~g} \mathrm{~L}^{-1}$ salinity for brackish water irrigation can significantly reduce $E T$ and improve the $W U E_{\mathrm{i}}$, although there was a slight decrease in $P_{n}, T_{t}, C_{i}$ and $Y$ compared with the same amount of fresh water irrigation. In terms of drought and salt stress, the FBB was found to be a better irrigation management strategy compared to FFD because it had more favorable effect on improving the $Y$ and $W U E_{i}$ and preventing the mass accumulation of soil salt. In addition, the results showed that the $\mathrm{Na}^{+} / \mathrm{K}^{+}$ratios, proline and soluble sugar concentrations increased significantly under salt stress, and these changes were physiological responses of winter wheat to salt stress. Our finding offers important information for understanding the mechanisms by which salinity affects physiological activity of wheat, which would be helpful for exploring the appropriate irrigation scheme for brackish water for winter wheat in the further.

The results of this study are only the experimental results of specific irrigation mineralization $\left(3 \mathrm{~g} \mathrm{~L}^{-1}\right)$ for two years, but the change rules of winter wheat growth physiological indexes and soil water and salt indexes under different irrigation mineralization, and the safety of long-term brackish water irrigation need further experimental research. In addition, subsurface drainage and salt drainage technology can be considered to regulate water and salt in this region, which can not only quickly remove the surplus water in the soil, reduce the groundwater level, prevent soil salt return, create a good growth environment for crops, but also enhance rainfall and irrigation to leach salt.

Acknowledgements. This project was jointly supported by the National Natural Science Foundation of China (No.51509105) and Shandong Provincial Natural Science Foundation, China (ZR2014EEQ020). 


\section{REFERENCES}

[1] Bao, S. D. (2000): Soil agrochemical analysis. - China Agriculture Press, Beijing.

[2] Basile, A., Buttafuoco, G., Mele, G., Tedeschi, A. (2012): Complementary techniques to assess physical properties of a fine soil irrigated with saline water. - Environment Earth Science 66: 1797-1807.

[3] Ben-Hur, M., Li, F. H., Keren, R., Ravina, I., Shalit, G. (2001): Water and salt distribution in a field irrigated with marginal water under high water table conditions. - Soil Science Society of America Journal 65: 191-198.

[4] Berry, J. A., Downton, W. J. S. (1982): Environmental regulation of photosynthesis. - In: Govindjee (ed.) Photosynthesis V2: Development, Carbon Metabolism, and Plant Productivity. Academic Press, pp. 263-343.

[5] Boese, S., Jung, M., Carvalhais, N., Reichstein, M. (2017): The importance of radiation for semiempirical water-use efficiency models. - Biogeosciences 14: 1-22.

[6] Chen, S. Y., Shao, L.W., Sun, H. Y., Zhang, X. Y., Li, Y. F. (2016): Effect of brackish water irrigation on salt balance and yield of both winter wheat and summer maize. Chinese Journal of Eco-Agriculture 24: 1049-1058.

[7] Estrada, B., Aroca, R., Barea, J. M., Ruiz-Lozano, J. M. (2013): Native arbuscular mycorrhizal fungi isolated from a saline habitat improved maize antioxidant systems and plant tolerance to salinity. - Plant Science 201: 42-51.

[8] Farquhar, G. D., Sharkey, T. D. (1982): Stomatal conductance and photosynthesis. Annual Review of Plant Physiology 33: 317-345.

[9] Gadallah, M. A. A. (1999): Effect of proline and glycinebetaine on Vicia faba response to salt stress. - Biologia Plantarum 42: 249-257.

[10] Harding, R., Mahler, R., Curran, E. (1996): Saline irrigation water and citrus production. California Agriculture, pp. 3348-3352.

[11] Irigoyen, J. J., Einerich, D. W., Sánchez-Díaz, M. (2010): Water stress induced changes in concentrations of proline and total soluble sugars in nodulated alfalfa (Medicago sativd) plants. - Physiology Plantarum 84: 55-60.

[12] Kelley, W. P. (1963): Use of saline irrigation water. - Soil Science 95: 385-391.

[13] Khan, A. A., McNeilly, T., Collins, C. (2000): Accumulation of aminoacids, proline, and carbohydrates in response to aluminum and manganese stress in maize. - Journal of Plant Nutrition 23: 1303-1314.

[14] Khan, M. A. (2001): Experimental assessment of salinity tolerance of Ceriops tagal seedlings and saplings from the Indus delta, Pakistan. - Aquatic Botany 70: 259-268.

[15] Kiani, A. R., Mirlatifi, S. M. (2012): Effect of different quantities of supplemental irrigation and its salinity on yield and water use of winter wheat (Triticum aestivum). - Irrigation Drainage 61: 89-98.

[16] Liu, X. W., Feike, T., Chen, S. Y., Shao, L. W., Sun, H. Y., Zhang, X. Y. (2016): Effect of saline irrigation on soil salt accumulation and grain yield in the winter wheat-summer maize double-cropping system in the low plain of north China. - Journal of Integrative Agriculture 15: 2886-2898.

[17] Liu, B., Wang, S., Kong, X., Liu, X., Sun, H. (2019): Modeling and assessing feasibility of long-term brackish water irrigation in vertically homogeneous and heterogeneous cultivated lowland in the North China Plain. - Agriculture Water Management 211: 98110.

[18] Meloni, D. A., Gulotta, M. R., Martinez, C. A., Oliva, M. A. (2004): The effect of salt stress on growth, nitrate reduction and proline and glycinebetaine accumulation in Prosopis alba. - Brazilian Journal of Plant Physiology 16: 39-46.

[19] Moreno, F., Cabrera, F., Fernández-Boy, E., Giron, I. F., Fernandez, J. E., Bellido, B. (2007): Irrigation with saline water in the reclaimed marsh soils of south-west Spain: impact on soil properties and cotton and sugar beet crops. - Agriculture Water Management 48: $133-150$. 
[20] Parida, A. K., Das, A. D. (2005): Salt tolerance and salinity effect on plants: a review. Ecotoxicology and environmental safety 60: 324-349.

[21] Patade, V. Y., Bhargava, S., Suprasanna, P. (2011): Salt and drought tolerance of sugarcane under iso-osmotic salt and water stress: growth, osmolytes accumulation, and antioxidant defense. - Journal of Plant interactions 6: 275-282.

[22] Radhouane, L. (2013): Agronomic and physiological responses of pearl millet ecotype (Pennisetum glaucum (L.) R. Br.) to saline irrigation. - Emirates Journal of Food and Agriculture 25: 109-116.

[23] Rahman, M. S., Miyake, H., Takeoka, Y. (2002): Effect of exogenous glycinebetaine on growth and ultrastructure of salt-stressed rice seedlings (Oryza sativa L.). - Plant Production Science 5: 33-44.

[24] Selim, D. A. F. H., Nassar, R. M. A., Boghdady, M. S., Bonfill, M. (2019): Physiological and anatomical studies of two wheat cultivars irrigated with magnetic water under drought stress conditions. - Plant Physiology and Biochemistry 135: 480-488.

[25] Shani, U., Dudley, L. M. (2001): Field studies of crop response to water and salt stress. Soil Science Society of America Journal 65: 1522-1528.

[26] Singh, A. (2014): Conjunctive use of water resources for sustainable irrigated agriculture. - Journal of Hydrology 519: 1688-1697.

[27] Soothar, R. K., Zhang, W. Y., Zhang, Y. Q., Tankari, M., Mirjat, U., Wang, Y. S. (2019a): Evaluating the performance of SALTMED model under alternate irrigation using saline and fresh water strategies to winter wheat in the North China Plain. - Environmental Science and Pollution Research 26: 34499-34509.

[28] Soothar, R. K., Zhang, W., Liu, B., Tankari, M., Wang, Y. (2019b): Sustaining Yield of Winter Wheat under Alternate Irrigation Using Saline Water at Different Growth Stages: A Case Study in the North China Plain. - Sustainability 11: 4564.

[29] Wang, Q. J., Xu, Y.Z., Wang, J. D., Wang, Y. P., Jiang, Q. H. (2002): Application of saline and slight saline water for farmland irrigation. - Irrigation Drainage 21: 73-77.

[30] Wang, S. J., Huang, G. H., Yang, J. G., Wang, J., Tai, R. K., Meng, L. G. (2010): Effect of irrigation with saline water on water-salt dynamic and spring wheat yield. - Transactions of the CSAE 26: 27-33.

[31] Wiedenfeld, B. (2008): Effect of irrigation water salinity and electrostatic water treatment for sugarcane production. - Agriculture Water Management 95: 85-88.

[32] Xu, T., Yan, D., Weng, B., Bi, W., Do, P., Liu, F., Wang, Y., Ma, J. (2018): The effect evaluation of comprehensive treatment for groundwater overdraft in Quzhou county, China. - Water 10: 874-892.

[33] Zhu, C. L., Qing, C., Huang, M. Y., Zhai, Y. M., Lv, W. (2018): Effect of Alternate Irrigation with Fresh and Slight Saline Water on Physiological Growth of Summer Maize in Coastal Reclamation Area. - Transactions of the Chinese Society for Agricultural Machinery 49: 253-261. 